\title{
COMPRESSION TEXTURE OF POWDERED ROCK-SALT
}

\author{
H.-G. BROKMEIER \\ Department of Physical Metallurgy, Technical University Clausthal \\ and GKSS Research Center, Postfach 1160, D-2054 Geesthacht, FRG
}

\section{INTRODUCTION}

The compression of powdered materials occurs in various preparation techniques, engineering processes and also in nature. In the case of phase analysis by X-ray diffraction, powder compression is the standard technique for sample preparation. The first steps in powder metallurgical techniques are often the homogeneous mixing and compressing of powders. In sedimentation processes, the sedimented particles will be compacted by a pressure of superpositions. In all these cases compression takes place at relatively low pressures, so that a state of partial deformation will not yet be reached. Therefore grain shape will play the dominant role in the formation of preferred orientations. It is well known that in the case of layered materials such as graphite or mica, a basal plane texture with a high degree of preferred orientation is formed. Investigations have been carried out to study the compression texture of cubic rock-salt $(\mathrm{NaCl})$ with the aim of clarifying the influence of the grain size and the compression conditions on the preferred orientation.

\section{EXPERIMENTAL}

Natural rock-salt from the Asse mine $20 \mathrm{~km}$ south of Braunschweig (FRG) was milled and sieved into seven grain size fractions $(100-125 \mu \mathrm{m}, 125-180 \mu \mathrm{m}$, 180-250 $\mu \mathrm{m}, 250-315 \mu \mathrm{m}, 315-500 \mu \mathrm{m}, 500-1000 \mu \mathrm{m}$ and 1000-2000 $\mu \mathrm{m}$ ). Additional minerals present had volume fractions lower than $0.2 \%$, indicating a nearly monomineralic material. The compression experiments were performed with an uniaxial laboratory press having a round steel matrix. To study the influence of compression two types of experiments were carried out. The first type was a short time pressing with different pressures between $10 \mathrm{MPa}$ and $50 \mathrm{MPa}$. Type 2 was a periodic compression with up to 20 intervals at a constant pressure of 20 MPa. The final form of the pressed samples was cylindrical with $20 \mathrm{~mm}$ in high and $20 \mathrm{~mm}$ in diameter. Depending on the compression pressure, an experimental density of $80 \%-99 \%$ was obtained.

The texture determination was carried out with thermal neutrons (1), using the D1S Instrument at the Hahn-Meitner Institut in Berlin. The application of neutrons was chosen because of the relatively high transmission of the neutron 
beam, see for example Bacon (2). Hence, the bulk texture (3) of the whole sample volume of $6.28 \mathrm{~cm}^{3}$ can be measured. Moreover, the influence of the coarse grained material on the grain statistics can be neglected, so that the texture of the grain size fraction $1000 \mu \mathrm{m}-2000 \mu \mathrm{m}$ can be measured with the same accuracy as the texture of the fine grained material $(100 \mu \mathrm{m}-125 \mu \mathrm{m})$. To characterize the texture, three $\mathrm{NaCl}$ pole figures of each sample were measured (111 ),(200), (220). Based on the preparation procedure the sample symmetry was rotative. Therefore, each pole figure measurement consisted of a $\chi$-scan with $\Delta \chi=5.0^{\circ}$. Figure 1 shows the pole figure measurement of the $(200)$ reflection. The data were analysed using the standard normalisation (4) which gives the degree of preferred orientation with respect to the random texture.

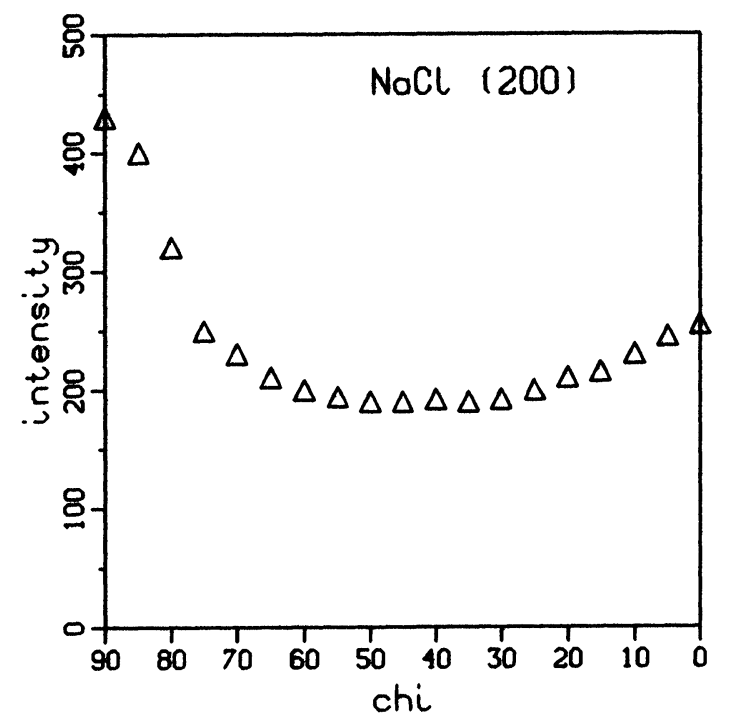

Figure 1 Pole figure measurement of $\mathrm{NaCl}(200)$

\section{RESULTS AND DISCUSSION}

Depending on the cubic crystal structure and on the (100) cleavage, grain boundary gliding is predominant in $\mathrm{NaCl}$ structures. Microscopicy studies show the grain shapes of the rock-salt grains after milling to be cubic, rectangular or even tubular. Most of the surfaces were (100) cleavage planes. Hence, in all samples the predicted $\langle 100\rangle$ fibre texture was observed. This result agrees with the experiments of Dobson and Wilman (5), but the degree of preferred orientation will be influenced by the grain size and the compression pressure. The results of the compression experiments in terms of multiple random (mrd) are listed in table 1. Column 1 gives the average diameter of the volume fraction; columB 2-6 gives the degree of orientation as multiple random (mrd $=I / I_{0}$ ). Figure 2 shows graphically the influence of the grain size at constant pressure on the texture. 
Table 1 Degree of preferred orientation $\left(\operatorname{mrd}=\mathrm{I} / \mathrm{I}_{0}\right)$

\begin{tabular}{|c|c|c|c|c|c|}
\hline \multirow{2}{*}{$\begin{array}{l}\text { diameter } \\
\text { (average) }\end{array}$} & \multicolumn{5}{|c|}{ compression pressure $(\mathrm{MPa})$} \\
\hline & 10 & 20 & 30 & 40 & 50 \\
\hline $112 \mu \mathrm{m}$ & 1.05 & 1.09 & 1.11 & 1.13 & 1.13 \\
\hline $152 \mu \mathrm{m}$ & 1.09 & 1.07 & 1.15 & 1.15 & 1.11 \\
\hline $215 \mu \mathrm{m}$ & 1.18 & 1.17 & 1.20 & 1.16 & 1.16 \\
\hline $282 \mu \mathrm{m}$ & 1.21 & 1.22 & 1.26 & 1.27 & 1.21 \\
\hline $407 \mu \mathrm{m}$ & 1.36 & 1.26 & 1.31 & 1.32 & 1.24 \\
\hline $750 \mu \mathrm{m}$ & 1.59 & 1.62 & 1.56 & 1.46 & 1.47 \\
\hline $1500 \mu \mathrm{m}$ & 2.30 & 2.11 & 1.99 & 1.90 & 1.79 \\
\hline
\end{tabular}

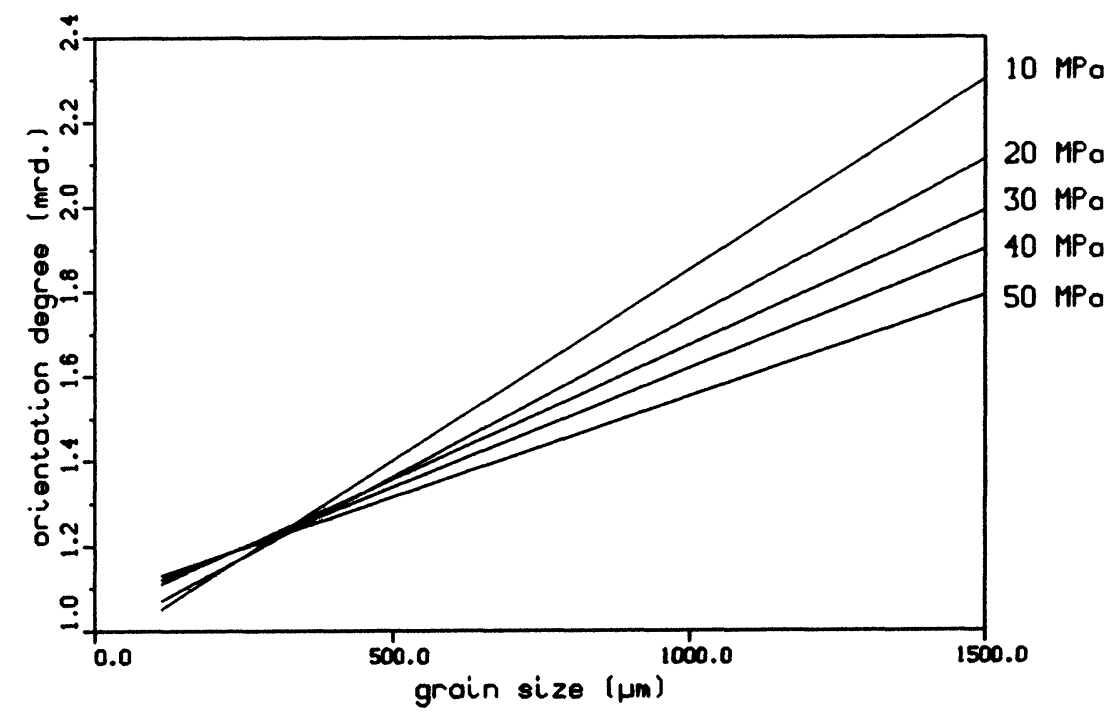

Figure 2 Orientation degree as a function of the grain size

It can be seen that the orientation degree is higher at larger grain size fractions. However, the increase of the orientation degree also depends on the pressure. The influence of the grain size on the preferred orientation is the higher the lower the pressure. This can be explained as follows:

1. The initial state of the powders depends on the grain size. Large grains tend to orientate more by filling up the laboratory press than smaller ones. Hence, the initial texture before compression increases with increasing grain size. 
2. The pore characteristics (number, distribution and size of the pores) has a strong influence on grain mobility. Therefore, small grains can rotate more than large grains.

3. The bulk texture gives an average of all local textures. In particular, the difference in surface texture (texture of the contact zone) and in deep texture (texture of the inner part) will have an influence. This influence is based on the different number of grains for each grain size fraction which belong to the surface or to the inner part of the sample.

A second point of discussion is the influence of the compression pressure on the degree of orientation. Figure 3 shows two curves which illustrate the change of the orientation degree in relation to the compression pressure.

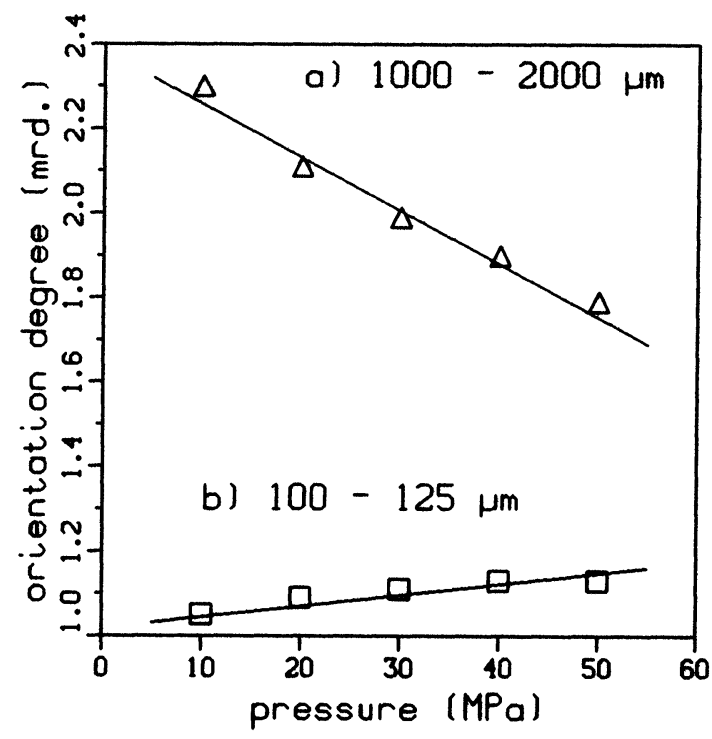

Figure 3 Orientation degree as a function of the pressure

a.) $1000-2000 \mu \mathrm{m} \mathrm{b}$.) $100-125 \mu \mathrm{m}$

In the case of the fraction $1000-2000 \mu \mathrm{m}$, a decrease of the orientation degree is noted with increasing pressure. On the other hand the smallest fraction $100-125 \mu \mathrm{m}$ shows an increase of the orientation degree with increasing pressure. The behaviour of the other fractions lies between the two extreme cases described above. The main point in the explanation is the starting texture (see above). Large grains have a high starting texture while small grains have a low starting texture near to random. Another point is the ratio of the grain size to the pore size which influences the mobility of the grains. Large grains cannot rotate into the ideal (100) position; they can only fill the pores, and the degree of preferred orientation decreases. In the case of small grains the mobility is higher. A third aspect is the effective penetration depth of the pressure force. An increase in pressure ensures that all parts of the sample experience compression. Especially in fine-grained materials a more homogeneous compaction is achieved. 
The orientation of the fine-grained rock-salt is not only in the surface region but also in the bulk. Hence, the bulk texture increases.

The last type of experiment, performed in this series, demonstrates the influence of interval pressing up to 20 times at constant pressure. The results of the investigation of the grain size fraction $500-1000 \mu \mathrm{m}$ are shown in figure 4 .

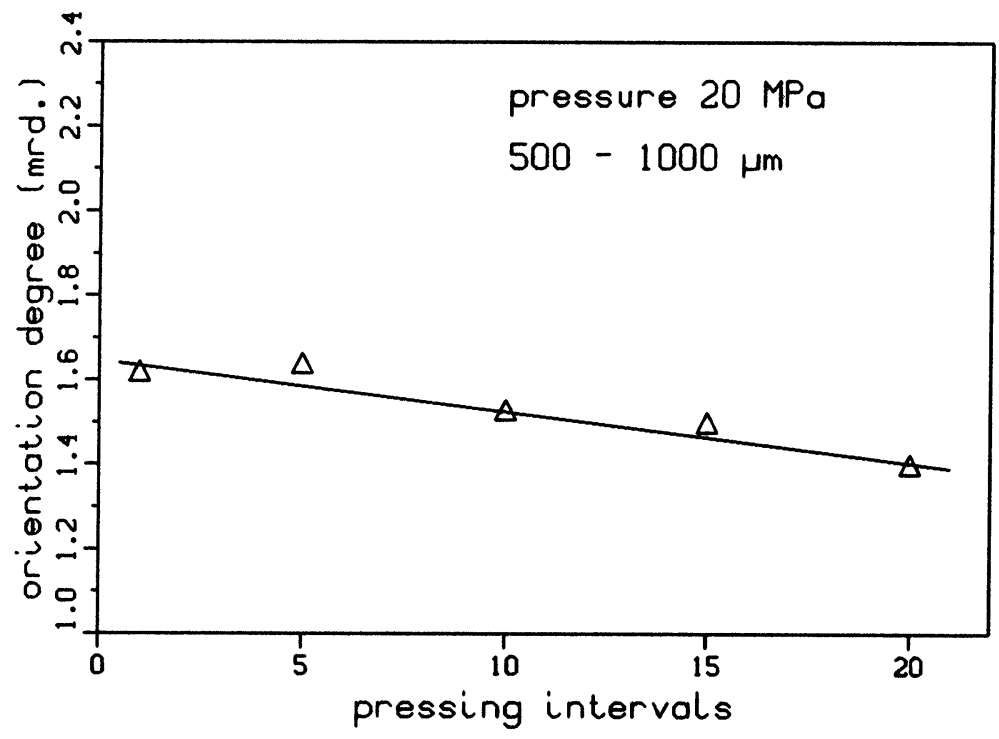

Figure 4 Orientation degree as a function of pressing intervals

The sample has a relatively high starting texture (1 time $20 \mathrm{MPa})$. Increasing the number of intervals leads to a decrease in the measured degree of texture. In correlation to short time pressing, interval pressing leads to the same tendency in texture development as an increase of the pressing force (see figure 3a).

\section{ACKNOWLEDGEMENTS}

The author would like to thank the Hahn-Meitner Institut in Berlin for the support with neutron diffraction, especially Dr. H.A. Graf. This was funded by the Land Niedersachsen of the Federal Republic of Germany (FRG).

\section{REFERENCES}

1. H.-G. Brokmeier, Phd. Thesis (Technische Universität Clausthal, 1983)

2. G.E. Bacon, Neutron Diffraction, Clarendon Press, Oxford 1975)

3. H.J. Bunge, Textures Microstruc.,10, 265 (1989)

4. G. Wassermann, J. Grewen, Texturen metallischer Werkstoffe (Springer, Berlin 1962)

5. P.S. Dobson and H. Wilman, Acta. Cryst. 15, 794 (1962) 